\title{
lodixanol supplementation during sperm cryopreservation improves protamine level and reduces reactive oxygen species of canine sperm
}

\author{
Dimas A. Abdillah, Erif M. N. Setyawan, Hyun Ju Oh, Kihae Ra, Seok Hee Lee, Min Jung Kim, Byeong Chun Lee* \\ Department of Theriogenology and Biotechnology, College of Veterinary Medicine, Seoul National University, Seoul 08826, Korea
}

\begin{abstract}
The objective of this study was to analyze the protective effects of iodixanol on dog spermatozoa during cryopreservation. The optimal concentration of iodixanol, $1.5 \%$, was determined using fresh spermatozoa and was applied in the following experiments. The $1.5 \%$ iodixanol group showed significantly increased sperm motility from that in the control $(p<0.05)$. Lower mitochondrial reactive oxygen species (ROS) modulator (ROMO1) and pro-apoptotic gene (BAX) expressions, together with higher expressions of protamine-2 (PRM2), protamine-3 (PRM3), anti-apoptotic B-cell lymphoma-2 (BCL2), and sperm acrosome associated-3 (SPACA3) genes were detected in the iodixanol-treated group. In addition, decreased protamine deficiency and cryocapacitation were observed in the treatment group. Our results show that supplementation with $1.5 \%$ iodixanol is ideal for reducing production of ROS and preventing detrimental effects during the canine sperm cryopreservation process, effects manifested as increased motility and reduced cryocapacitation in frozen-thawed spermatozoa.
\end{abstract}

Keywords: Dogs; Sperm; Cryopreservation; Reactive oxygen species; Protamine

\section{Introduction}

Sperm cryopreservation is an essential step for artificial insemination (AI), which is the most widely used assisted reproductive technology in Canidae. The main goal of sperm cryopreservation is to conserve the fertility of high genetic value organisms or to preserve endangered species [7]. In addition, sperm cryopreservation for AI can prevent sexually transmitted diseases such as brucellosis and herpes virus infections [10]. In wild animals, AI with cryopreserved spermatozoa has had a considerable effect in conservation management of African wild dogs [5]. Moreover, AI using cryopreserved spermatozoa provides a number of potential advantages including reduction of stress associated with transportation of animals, avoiding resistance to copulation due to behavioral issues (female aggressiveness), and overcoming quarantine restrictions placed on live animals [8].

During the cryopreservation process, osmotic pressure and ice formation can cause cryoinjury and loss of viability and sperm function post-thawing [25]. Osmotic stress following cell dehydration induces destabilization of sperm membranes by reducing their fluidity, and this is exacerbated by excessive production of endogenous and exogenous reactive oxygen species (ROS) [1,13]. An imbalance between ROS production during cryopreservation and antioxidant defenses of spermatozoa result in oxidative stress [3] and lipid peroxidation of plasma membranes that contain large amounts of polyunsaturated fatty acids [35]. Consequently, important cell components such as DNA are damaged by cryopreservation [16]. On the other hand, complete elimination of ROS is also detrimental because some ROS are required for normal reproductive events [15]. Thus, maintaining appropriate oxidative stress and ROS levels is necessary during sperm cryopreservation and thawing.

Protamine binding of large segments of DNA is stronger than histone binding [6] and results in the construction of toroids, which are condensed DNA strands that protect sperm chromatin from oxidative damage [28]. After a freeze-thaw cycle, bonding of disulfide bridges in protamine is disturbed, and DNA damage is increased [12]. In addition, less compaction of DNA and more susceptibility to damage has been observed in frozen-thawed canine spermatozoa [4], and a higher level of sperm DNA damage reduces the quality of the embryo [33]. Insufficient sperm chromatin content is also 
correlated with an elevated early pregnancy loss risk after in vitro fertilization (IVF) and intracytoplasmic sperm injection [39]. Accordingly, conserving protamines during sperm cryopreservation and thawing is important to protect sperm chromatin and support a pregnancy.

Iodixanol is normally used as an x-ray contrast medium, because it is nontoxic, non-ionic, dimeric, and hexaiodinated $[11,21]$. Adding iodixanol could change ice crystal formation into a intracellular dendritic form, which results in a more sperm-friendly environment [26]. However, the mechanism associated with iodixanol protecting canine sperm from DNA damage during cryopreservation has not yet been determined. We hypothesized that iodixanol treatment conserves sperm protamines to help maintain DNA integrity during cryopreservation.

\section{Materials and Methods}

All chemicals used in this experiment were purchased from Sigma-Aldrich (USA) unless otherwise stated.

\section{Animal use and semen preparation}

The subjects used in this experiment were 4 healthy and mature male beagles, 4 to 6 years old, and weighing 8 to $10 \mathrm{~kg}$. The dogs were maintained separately in indoor cages. Their housing, animal care facilities and procedures followed standards established by the Committee for Accreditation of Laboratory Animal Care at Seoul National University. The Guide for the Care and Use of Laboratory Animals at Seoul National University was the standard for animal use in this study (approval No. SNU-160602-6-4). Semen samples from the dog were collected twice a week and only ejaculates having sperm concentrations $\geq 100 \times 10^{6} / \mathrm{mL}$, motility $\geq 70 \%$, viability $\geq 80 \%$, and normal morphology $\geq 80 \%$ were used.

\section{Determination of iodixanol concentration}

Optiprep (60\% iodixanol in water) was mixed into the first buffer (24 g/L Tris [hydroxymethyl] aminomethane, $14 \mathrm{~g} / \mathrm{L}$ citric acid, $8 \mathrm{~g} / \mathrm{L}$ fructose, and $0.15 \mathrm{~g} / \mathrm{L}$ kanamycin sulfate in distilled water [pH 6.6, $290 \mathrm{mOsm}])$. The ejaculates were collected from 4 male beagles and pooled into $15 \mathrm{~mL}$ tubes. The pooled ejaculates were washed by centrifuging at $100 \times \mathrm{g}$ for 1 $\mathrm{min}$ at room temperature to remove debris [24]. The debris was the pellet in the tube bottom and sperm was the supernatant. The supernatant was divided into 4 aliquots with different concentrations of Optiprep; $0 \%$ (control), $1 \%$ ( $0.6 \%$ iodixanol), $2.5 \%(1.5 \%$ iodixanol $)$, and $5 \%$ (3\% iodixanol) treatment groups.

Afterward, motility and kinematic parameters were evaluated. Approximately $10 \mu \mathrm{L}$ of sperm was dropped onto a slide and mounted with a coverslip. Spermatozoa in 5 different fields were assessed and the kinematic parameters of at least
200 motile spermatozoa were tracked in each experiment by using a sperm analysis imaging system (FSA2011 premium edition version 2011; Medical Supply, Korea).

Additionally, sperm viability was examined by using an eosin-nigrosin staining method. Briefly, sperm suspension smears were made after adding the stain (1:1) to the first buffer with iodixanol. The sperm sample was then spread onto a slide and dried in air. Sperm viability was analyzed for at least 200 cells. Thereafter, the optimal concentration was chosen and used for the following experiment to investigate the effects of iodixanol on sperm cryopreservation.

\section{Sperm freezing and thawing}

The second experiment was performed to investigate the effects of iodixanol on cryopreservation. An equal volume of the first buffer was added to pooled ejaculates for washing and centrifuged at $700 \times \mathrm{g}$ for $5 \mathrm{~min}$ at room temperature. The pellet was resuspended by adding the first buffer to achieve a sperm concentration of $200 \times 10^{6} \mathrm{sperm} / \mathrm{mL}$. Each aliquot was mixed with the second buffer $(40 \%[\mathrm{v} / \mathrm{v}]$ egg yolk, $54 \%[\mathrm{v} / \mathrm{v}]$ first buffer, and $6 \%[\mathrm{v} / \mathrm{v}]$ glycerol) and iodixanol. The suitable volume of the second buffer was added to produce $14 \%, 19 \%$, $27 \%$, and $40 \%$ of the total volume and loaded sequentially at 30 sec intervals as described in a previous study [29]. Straws $(0.25$ $\mathrm{mL}$; Minitub, Germany) were used to store the extended sperm suspension and were incubated at $4^{\circ} \mathrm{C}$ for $1 \mathrm{~h}$ for equilibration. Subsequently, the straws were placed horizontally $2 \mathrm{~cm}$ above the surface of liquid nitrogen $\left(\mathrm{LN}_{2}\right)$ for $15 \mathrm{~min}$ then plunged into the $\mathrm{LN}_{2}$. After one week, the sperm was thawed in a water bath at $60^{\circ} \mathrm{C}$ for $7 \mathrm{sec}$. The sperm samples were then diluted (1:5) by adding the first buffer to obtain $14 \%, 19 \%, 27 \%$, and finally $40 \%$ of the total volume. Thawed sperm motility and kinematic parameters were determined with a sperm analysis imaging system as mentioned in the 'Determination of iodixanol concentration' section. Then, all thawed spermatozoa were evaluated as described in the following sections.

\section{Gene expression analysis and chromomycin A3 staining}

Briefly, triplicates from five pairs of canine frozen-thawed sperm samples from the control and from treatment groups were used for RNA measurement. Real-time quantitative polymerase chain reaction (RT-qPCR) was employed to assess transcript abundances using oligonucleotide primer sequences, all of which are listed in Table 1. The mRNA expressions of apoptotic genes ( $B C L 2$ and $B A X)$, a mitochondrial ROS modulator (ROMOI) gene, genes for measuring protamine levels (PRM2 and PRM3), and a sperm acrosome associated-3 (SPACA3) gene were analyzed. Total RNA was extracted using Trizol reagent (Invitrogen, USA), according to the manufacturer's protocol, and complementary DNA was produced using Maxime RT PreMix (Intronbio, Korea). The RT-qPCR assays were performed using a Step One Plus 
Table 1. Primer sequences used for gene expression analysis in spermatozoa treated with iodixanol during cryopreservation

\begin{tabular}{|c|c|c|c|}
\hline Gene & Primer sequence $\left(5^{\prime}-3^{\prime}\right)$ & Product size (bp) & GenBank accession No. \\
\hline \multirow[t]{2}{*}{$A C T B$} & F: GGCATCCTGACCCTGAAGTA & 148 & NM_001195845.1 \\
\hline & R: GGTGTGGTGCCAGATCTTCT & & \\
\hline \multirow[t]{2}{*}{$B C L 2$} & F: CTCСTGGСTGTCTCTGAAGG & 120 & NM_001002949.1 \\
\hline & R: GTGGCAGGCCTACTGACTTC & & \\
\hline \multirow[t]{2}{*}{$B A X$} & F: GACGGССТССТСТССТАСТT & 145 & NM_001003011.1 \\
\hline & R: GGTGAGTGACGCAGTAAGCA & & \\
\hline \multirow[t]{2}{*}{ ROMO1 } & F: TGTCTCAGGATCGGAATGCG & 100 & XM_534406.4 \\
\hline & R: TCCCGATGGCCATGAATGTG & & \\
\hline \multirow[t]{2}{*}{ PRM2 } & F: AGGAGGAGATACAGGAGGTGC & 148 & NM_001287148 \\
\hline & R: CTTGCAAACTCAGGGCTTGG & & \\
\hline \multirow[t]{2}{*}{ PRM3 } & F: GGCCACGAATCCTCCATGGA & 128 & XM 847270.4 \\
\hline & R: AGCTССТССТСТTССТССТ & & \\
\hline \multirow[t]{2}{*}{ SPACA3 } & F: GGATTTCGGCATGGAGGGAT & 149 & NM_001197087.1 \\
\hline & R: ACTTCCGGCTGTTGATCTGG & & \\
\hline
\end{tabular}

$F$, forward; $R$, reverse.

Real-Time PCR System (Applied Biosystems, USA) and each target gene's expression was quantified relative to that of the internal gene $(A C T B)$ using the equation, $\mathrm{R}=2^{-[\Delta \mathrm{Ct} \text { sample }-\Delta \mathrm{Ct}}$ control] [17].

Frozen-thawed canine sperm smears were fixed in methanol/glacial acetic acid $(3: 1)$ at $4{ }^{\circ} \mathrm{C}$ for $5 \mathrm{~min}$. Control and treatment group slides were treated for 20 min with $100 \mu \mathrm{L}$ $\mathrm{CMA}_{3}$ solution. The $\mathrm{CMA}_{3}$ solution contained $0.25 \mathrm{mg} / \mathrm{mL}$ $\mathrm{CMA}_{3}$ in McIlvane's buffer (pH 7.0) supplemented with $10 \mathrm{mM}$ $\mathrm{MgCl}_{2}$. Slides were then rinsed in McIlvain's buffer and air dried. Microscopic analysis of slides was performed by measuring fluorescence with a Zeiss microscope at 1,000× magnification. A total of 200 spermatozoa were randomly evaluated on each slide. Evaluation of $\mathrm{CMA}_{3}$ was completed by identifying two types of staining patterns: bright green fluorescence of the sperm head $\left(\mathrm{CMA}_{3}\right.$ positive/abnormal chromatin packaging) and dull green staining $\left(\mathrm{CMA}_{3}\right.$ negative/normal chromatin packaging) of the sperm head.

\section{Sperm capacitation test}

The contents of one cryopreserved straw were divided into 2 aliquots after thawing in a water bath at $37^{\circ} \mathrm{C}$ for $30 \mathrm{sec}$. Cryocapacitation was analyzed using the first aliquot, while capacitation ability after thawing was analyzed using the second aliquot.

The first aliquot was diluted by adding 1 part semen to 9 parts $0.9 \% \mathrm{NaCl}$ then an equal volume of trypan blue $0.27 \%(\mathrm{v} / \mathrm{v})$ was added and the combination was mixed on a slide. Sperm smears were then fixed in a $37 \%$ formaldehyde solution for 2 min, then rinsed with distilled water. The Giemsa stock solution was freshly made by adding the stain to distilled water. Slides were dipped in $7.5 \%(\mathrm{v} / \mathrm{v})$ of Giemsa stain, air-dried in a vertical position, then cover-slipped. Slides were examined by examining 200 sperm cells with 5 independent replications. Assessment included counting the following: live spermatozoa with intact acrosomes (LSIA), live spermatozoa with damaged acrosomes (LSDA), dead spermatozoa with intact acrosomes (DSIA), and dead spermatozoa with damaged acrosomes (DSDA). The posterior part of the sperm head was dark blue in dead spermatozoa and sky-blue in live spermatozoa. Based on the color of anterior part sperm head, spermatozoa were divided into three groups, spermatozoa with intact acrosomes (purple), damage acrosomes (lavender), and those without acrosomes (pale gray). A canine capacitation medium (CCM) supplemented with $1.0 \mathrm{mM} \mathrm{MgCl}_{2}$ and $10 \mathrm{mM}$ progesterone was used for incubating the second aliquot for $4 \mathrm{~h}$, following incubation the second aliquot was stained to determine acrosomal status as described for the first aliquot [30].

\section{Mucus penetration test}

Modified synthetic oviduct fluid, as a surrogate mucus, was loaded into marked flat capillary tubes ( $10 \mathrm{~cm}$ long, $3 \mathrm{~mm}$ deep; Camlab, UK) that were sealed on one end. The filled capillary tubes were left standing vertically with the sealed end on top to allow removal of bubbles and check seal tightness. Then, the capillary tube was inserted into an Eppendorf tube containing a $100 \mu \mathrm{L}$ sperm suspension and laid horizontally for $2 \mathrm{~h}$ at room temperature. The spermatozoa reaching the $1 \mathrm{~cm}$ and $3 \mathrm{~cm}$ markers in the capillary tube were then counted.

\section{Statistical analysis}

All values are presented as mean \pm SEM values, and a $p$ value $<$ 0.05 was used to indicate statistical significance. For multiple comparisons among treatments and control groups, one-way 
analysis of variance and Tukey's multiple comparison tests were used. An unpaired $t$-test was used to compare results from the control and optimal iodixanol concentration groups. GraphPad Prism 5 (GraphPad Software, USA) was used for the statistical analyses.

\section{Results}

\section{Determination of optimum iodixanol concentration}

The percentage of fresh spermatozoa exhibiting motility in the $3 \%$ iodixanol group was significantly decreased $(48.0 \pm$ $6.3 \%$ ) compared to the percentages in the $0 \%, 0.6 \%$, and $1.5 \%$ iodixanol groups $(81.5 \pm 1.9 \%, 75.2 \pm 7.9 \%$, and $76.8 \pm 7.0 \%$, respectively; Table 2).

Four independent replicates were examined to evaluate the effect of iodixanol on the viability of fresh spermatozoa. The percentage of dead spermatozoa in the $1.5 \%$ iodixanol group was significantly lower $(4.1 \pm 0.4 \%)$ than in the control $(9.9 \pm$ $1.2 \%)$ and $3 \%$ iodixanol $(11.1 \pm 1.4 \%)$ groups (Fig. 1). There was no significant difference between the $0.6 \%$ iodixanol and control groups.

Effect of iodixanol on frozen-thawed sperm motility, kinematic parameters, and mucus penetration test

The frozen-thawed sperm percentage exhibiting motility after treatment with $1.5 \%$ iodixanol was significantly higher $(54.0 \pm 0.9 \%)$ than that in the control group $(46.6 \pm 2.2 \%$; Table
3). There were no significant differences in linearity, amplitude of lateral head displacement, and straightness percentages between the treatment and control groups $(30.6 \pm 2.4 \%$ vs. 28.7 $\pm 2.2 \% ; 3.9 \pm 0.4 \mu \mathrm{m}$ vs. $3.4 \pm 0.4 \mu \mathrm{m} ; 56.1 \pm 2.6 \%$ vs. $57.0 \pm$ $1.9 \%$, respectively). The mucus penetration test results showed that sperm counts in the $1.5 \%$ iodixanol treatment group were

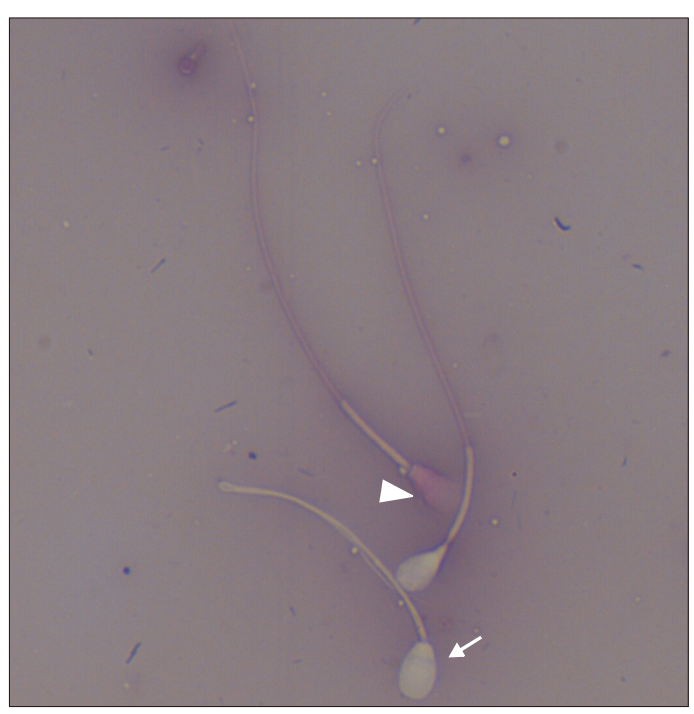

Fig. 1. Image of eosin-nigrosin stained sperm showing live (arrow) and dead (arrowhead) spermatozoa.

Table 2. Motility, linearity, dead canine spermatozoa, amplitude of lateral head displacement (ALH), and straightness with iodixanol treatment

\begin{tabular}{lccccc}
\hline \multicolumn{1}{c}{ Group } & Motility $(\%)$ & Linearity $(\%)$ & Dead sperm $(\%)$ & ALH $(\mu \mathrm{m})$ & Straightness $(\%)$ \\
\hline Control & $81.5 \pm 1.9^{\mathrm{a}}$ & $27.5 \pm 1.9$ & $9.9 \pm 1.2^{\mathrm{a}}$ & $4.7 \pm 0.1$ & $43.5 \pm 1.6$ \\
$0.6 \%$ iodixanol & $75.2 \pm 7.9^{\mathrm{a}}$ & $29.7 \pm 1.9$ & $8.6 \pm 1.4^{\mathrm{ab}}$ & $4.0 \pm 0.9$ & $44.1 \pm 1.4$ \\
$1.5 \%$ iodixanol & $76.8 \pm 7.0^{\mathrm{a}}$ & $29.2 \pm 2.2$ & $4.1 \pm 0.4^{\mathrm{b}}$ & $4.4 \pm 0.6$ & $44.3 \pm 1.7$ \\
$3 \%$ iodixanol & $48.0 \pm 6.3^{\mathrm{b}}$ & $25.6 \pm 3.7$ & $11.1 \pm 1.4^{\mathrm{c}}$ & $2.6 \pm 0.3$ & $41.7 \pm 1.9$ \\
\hline
\end{tabular}

Linearity, straightness of the path; Straightness, departure of the cell path from a straight line. ${ }^{a-c}$ Within a column, values with different superscripts differ significantly $(p<0.05,4$ replicates).

Table 3. Motility, linearity, amplitude of lateral head displacement (ALH), straightness, and sperm mucus penetration distance (cell) in frozen-thawed spermatozoa treated with/without iodixanol

\begin{tabular}{|c|c|c|c|c|c|c|}
\hline \multirow{2}{*}{ Group } & \multirow{2}{*}{ Motility (\%) } & \multirow{2}{*}{ Linearity (\%) } & \multirow{2}{*}{$\mathrm{ALH}(\mu \mathrm{m})$} & \multirow{2}{*}{ Straightness (\%) } & \multicolumn{2}{|c|}{$\begin{array}{l}\text { Sperm number in } \\
\text { mucus penetration distance }\end{array}$} \\
\hline & & & & & $1 \mathrm{~cm}$ & $3 \mathrm{~cm}$ \\
\hline Control & $46.6 \pm 2.2^{\mathrm{a}}$ & $28.7 \pm 2.2$ & $3.4 \pm 0.4$ & $57.0 \pm 1.9$ & $138.6 \pm 2.9^{\mathrm{a}}$ & $40.7 \pm 4.7^{\mathrm{a}}$ \\
\hline $1.5 \%$ iodixanol & $54.0 \pm 0.9^{b}$ & $30.6 \pm 2.4$ & $3.9 \pm 0.4$ & $56.1 \pm 2.6$ & $147.9 \pm 3.1^{b}$ & $56.4 \pm 5.3^{b}$ \\
\hline
\end{tabular}

Linearity, straightness of the path; Straightness, departure of the cell path from straight line. ${ }^{\mathrm{a}, \mathrm{b}}$ Within a column, values with different superscripts differ significantly $(p<0.05,6$ replicates). 
significantly higher at both the $1 \mathrm{~cm}$ and $3 \mathrm{~cm}$ markers (147.9 \pm 3.1 cells and $56.4 \pm 5.3$ cells, respectively) compared to those in the control group $(138.6 \pm 2.9$ cells and $40.7 \pm 4.7$ cells, respectively; Table 3 ).

\section{Effect of iodixanol on gene expression and $\mathrm{CMA}_{3}$ staining}

Treatment with $1.5 \%$ iodixanol during sperm cryopreservation significantly increased the $B C L 2$ transcript level by 1.6 -fold and decreased the $B A X$ level by 0.5 -fold compared with the control group (Fig. 2). Transcript levels of PRM2 and PRM3 significantly increased by 2.1 -fold and 1.8-fold, respectively, compared with the control. Gene expression of $R O M O 1$ was significantly reduced by 0.8 -fold compared with the control. Furthermore, SPACA3 gene expression significantly increased to about 1.4-fold of the control level.

$\mathrm{CMA}_{3}$ staining was performed for detection of protamine deficiency. Frozen-thawed spermatozoa treated with 1.5\% iodixanol showed significantly higher protamine levels than that in the control $(25.5 \pm 2.5 \%$ and $34.8 \pm 1.3 \%$, respectively; Fig. 3).

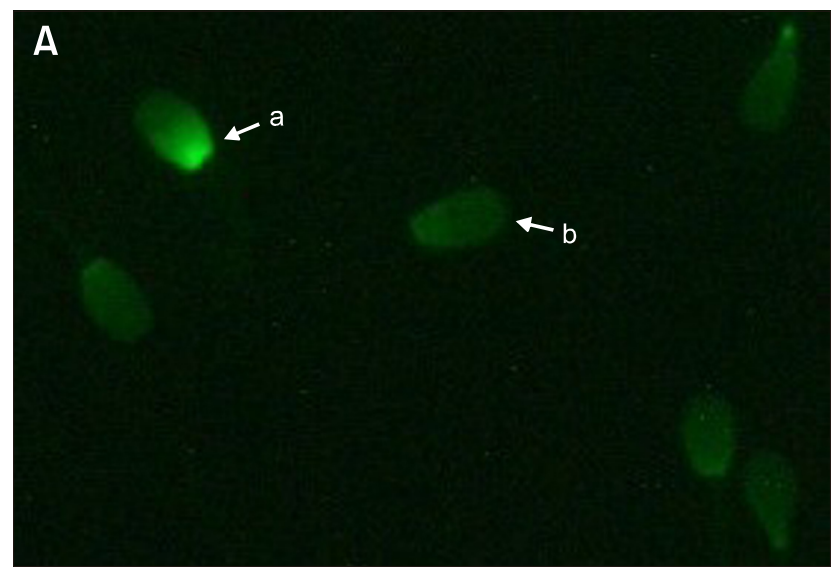

\section{Effect of $1.5 \%$ iodixanol on sperm capacitation}

The live sperm percentage post-thawing in the $1.5 \%$ iodixanol treatment group $(71.9 \pm 0.9 \%)$ was significantly greater than that in the control group $(59.1 \pm 0.3 \%)$. In addition, adding iodixanol to the buffer during cryopreservation also significantly reduced the dead sperm percentage compared to that in the control $(28.1 \pm 0.9 \% v s .40 .3 \pm 2.3 \%$, respectively).

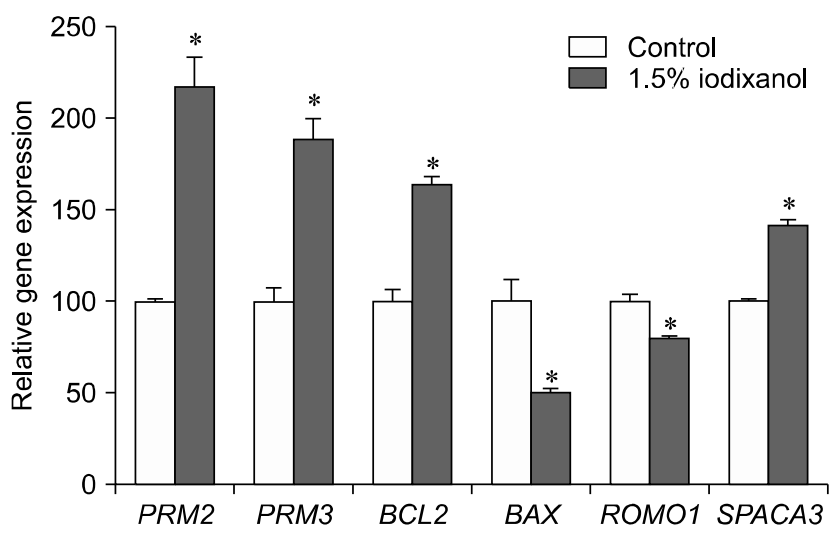

Fig. 2. Gene expression of apoptosis-, oxidative stress-, and protamine-related genes in control and $1.5 \%$ iodixanol-treated cryopreserved spermatozoa $(* p<0.05)$.

B

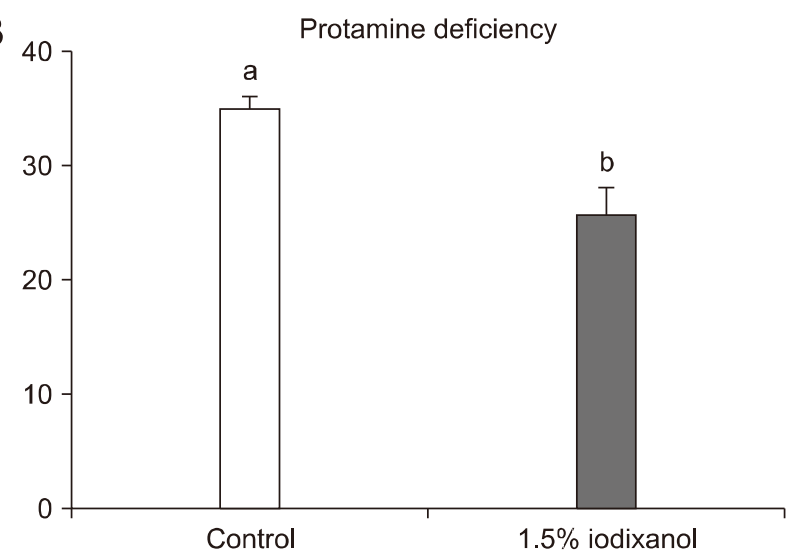

Fig. 3. (A) Results of $\mathrm{CMA}_{3}$ staining of sperm chromatin for protamine-deficient spermatozoa (a) and normal spermatozoa (b). (B) Quantification of $\mathrm{CMA}_{3}$ staining results for control- and 1.5\% iodixanol-treated spermatozoa ( ${ }^{\mathrm{a}, \mathrm{b}} p<0.05,5$ replicates).

Table 4. Acrosome staining results post-thawing and after incubation in canine capacitation medium (CCM)

\begin{tabular}{|c|c|c|c|c|c|c|}
\hline \multirow{2}{*}{ Group } & \multicolumn{2}{|c|}{ Post-thawing } & \multicolumn{4}{|c|}{ After incubation in CCM } \\
\hline & Live sperm (\%) & Dead sperm (\%) & LSIA (\%) & LSDA (\%) & DSIA (\%) & DSDA (\%) \\
\hline Control & $59.1 \pm 0.3^{\mathrm{a}}$ & $40.3 \pm 2.3^{\mathrm{a}}$ & $0.0 \pm 0.0$ & $59.1 \pm 0.7^{\mathrm{a}}$ & $13.6 \pm 1.0$ & $26.5 \pm 1.2^{\mathrm{a}}$ \\
\hline $1.5 \%$ iodixanol & $71.9 \pm 0.9^{b}$ & $28.1 \pm 0.9^{b}$ & $0.0 \pm 0.0$ & $65.8 \pm 1.1^{b}$ & $12.8 \pm 1.0$ & $21.4 \pm 0.9^{b}$ \\
\hline
\end{tabular}

LSIA, live spermatozoa with intact acrosome; LSDA, live spermatozoa with damaged acrosome; DSIA, dead spermatozoa with intact acrosome; DSDA, dead spermatozoa with damaged acrosome. ${ }^{\mathrm{a}, \mathrm{b}}$ Within a column, values with different superscripts differ significantly $(p<0.05,5$ replicates). 
After incubation for $4 \mathrm{~h}$ in CCM, all sperm acrosomes in both the treatment and control groups were lost. The percentage of LSDA in the treatment group was significantly higher than that in the control $(65.8 \pm 1.1 \%$ and $59.1 \pm 0.7 \%$, respectively). In the treatment group, the DSDA percentage was significantly lower than that in in the control $(21.4 \pm 0.9 \%$ vs. $26.5 \pm 1.2 \%$, respectively) as shown in Table 4.

\section{Discussion}

Generation of ROS is a source of problems for mammalian sperm viability, especially during cryopreservation [23] in which chromatin damage can result [16]. In this study, iodixanol was used as a cryoprotectant to alleviate such problems. To minimize the direct effects of iodixanol on sperm cell metabolism, we determined the optimal concentration of iodixanol using fresh spermatozoa and a method described in a previous study [22]. The reduced motility and increased proportions of dead spermatozoa in 3\% iodixanol (Table 2) might be due to a toxic effect of iodixanol on spermatozoa. The optimal iodixanol concentration found in our study was $1.5 \%$ (Table 3 ), which is similar to those for bovine [26] and buffalo [34] and comparable to ram [5], rats [19], spermatozoa. Ice crystal formation alteration in a non-colligative manner and elevation of glass transition temperature are possible mechanisms for obtaining an optimal environment for freezing [26]. It seems that a loose net of dendritic ice, as created by $1.5 \%$ iodixanol, was suitable in dogs and cattle due to canine and bovine spermatozoa similarities in retinoic acid receptors, which support sperm function and structure [18]. Based on our results, $1.5 \%$ iodixanol was chosen for iodixanol treatment of canine spermatozoa in the subsequent experiments.

Increased levels of the antiapoptotic gene $B C L 2$ and reduced levels of the proapoptotic gene $B A X$ in our results indicate that iodixanol reduced apoptosis during cryopreservation. $R O M O 1$ is a key gene for generating production of mitochondrial ROS [31], and a high level of endogenous ROS produced in the mitochondrial respiratory chain can cause random genetic mutations and lead to programmed cell death [36]. Our results suggest that iodixanol could protect mitochondria during the freezing and thawing process [32] and result in a ROS reduction. The advantage of a lower ROS production could be seen in the acrosome reaction [3]. Indeed, the number of viable spermatozoa and the percentage of viable spermatozoa with reacted acrosomes significantly increased in the treatment group (Table 4). The SPACA3 gene conserves subtract-binding sites for oligosaccharides of $\mathrm{N}$-acetylglucosamine existing in the extracellular matrix around the plasma membrane [20]. Increased SPACA3 expression in our study suggests that treating spermatozoa with iodixanol maintains their mechanical support, which could be the reason for the decreased apoptosis and increased mitochondrial protection observed in the iodixanol group.

Mechanical support in spermatozoa can also be important in conserving protamines in the sperm head. Protamine genes $P R M 2$ and PRM3 have roles in sperm motility. For example, impaired histones, disturbed DNA-hypercondensation, and immotility, consequences of serious membrane defects, are the results of $P R M 2$ deficiency in spermatozoa [27]. Low expression of the $P R M 2$ gene may also be related to abnormal morphology and entry to the apoptotic pathway [38]. The PRM3 gene is expressed in the cytoplasm and is important for sperm motility [14]. We confirmed the increased transcript expression of these protamine genes in the iodixanol treatment group (Fig. 2) by applying $\mathrm{CMA}_{3}$ stain (Fig. 3), a detector of nicked DNA and protamine-deficient, loosely packaged chromatin in spermatozoa. A significant negative correlation has been detected between $\mathrm{CMA}_{3}$ positivity and IVF efficiency [9].

The mucus penetration test shows the capability of spermatozoa to penetrate cervical mucus surrogates and it has been used to assess IVF and pregnancy results in vivo [2]. In our study, the increased motility and numbers of spermatozoa at distance results obtained during the mucus penetration test in the iodixanol group suggest that, compared to untreated spermatozoa, iodixanol-treated spermatozoa have more potential for producing fertilization and pregnancy success in the canine species.

In conclusion, $1.5 \%$ iodixanol supplementation of the second buffer protected canine spermatozoa during cryopreservation and maintained chromatin packing, effects that resulted in improved post-thaw motility and reduced cryocapacitation in frozen-thawed spermatozoa. Further studies, including examination of IVF and AI results, are necessary to fully describe the fertilizing capability of cryopreserved canine spermatozoa protected by the iodixanol supplementation.

\section{Acknowledgments}

This study was supported by RDA (CCAR, No. PJ013954022018), NRF (2018R1C1B6009536, No. 2016R1D1A1B0393219), Research Institute for Veterinary Science, and the BK21 Plus program.

\section{Conflict of Interest}

The authors declare no conflicts of interest.

\section{References}

1. Agarwal A, Virk G, Ong C, du Plessis SS. Effect of oxidative stress on male reproduction. World J Mens Health 2014, 32, $1-17$.

2. Aitken RJ. Sperm function tests and fertility. Int J Androl 2006, 29, 69-75. 
3. Aitken RJ, Baker MA, Nixon B. Are sperm capacitation and apoptosis the opposite ends of a continuum driven by oxidative stress? Asian J Androl 2015, 17, 633-639.

4. Chenoweth P, Lorton S. Animal Andrology: Theories and Applications. Centre for Agriculture and Bioscience International (CABI), Wallingford, 2014.

5. Cirit Ü, Bağiş H, Demir K, Agca C, Pabuccuoğlu S, Varişli Ö, Clifford-Rathert C, Agca Y. Comparison of cryoprotective effects of iodixanol, trehalose and cysteamine on ram semen. Anim Reprod Sci 2013, 139, 38-44.

6. De Jonge CJ, Barratt CLR. The Sperm Cell: Production, Maturation, Fertilization, Regeneration. Cambridge University Press, Cambridge, 2017.

7. Ehmcke J, Schlatt S. Animal models for fertility preservation in the male. Reproduction 2008, 136, 717-723.

8. England GC, Millar KM. The ethics and role of AI with fresh and frozen semen in dogs. Reprod Domest Anim 2008, 43 (Suppl 2), 165-171.

9. Esterhuizen AD, Franken DR, Lourens JGH, Prinsloo E, van Rooyen LH. Sperm chromatin packaging as an indicator of in-vitro fertilization rates. Hum Reprod 2000, 15, 657-661.

10. Farstad W. Artificial insemination in dogs. In: England GCW, von Heimendahl A (eds.). BSAVA Manual of Canine and Feline Reproduction and Neonatology. 2nd ed. pp 80-88, British Small Animal Veterinary Association, Gloucester, 2010.

11. Flinck A, Gottfridsson B. Experiences with iohexol and iodixanol during cardioangiography in an unselected patient population. Int J Cardiol 2001, 80, 143-151.

12. Flores E, Ramió-Lluch L, Bucci D, Femández-Novell JM, Peña A, Rodníguez-Gil JE. Freezing-thawing induces alterations in histone H1-DNA binding and the breaking of protein-DNA disulfide bonds in boar sperm. Theriogenology 2011, 76, 1450-1464.

13. Giraud MN, Motta C, Boucher D, Grizard G. Membrane fluidity predicts the outcome of cryopreservation of human spermatozoa. Hum Reprod 2000, 15, 2160-2164.

14. Grzmil P, Boinska D, Kleene KC, Adham I, Schlüter G, Kämper M, Buyandelger B, Meinhardt A, Wolf S, Engel W. Prm3, the fourth gene in the mouse protamine gene cluster, encodes a conserved acidic protein that affects sperm motility. Biol Reprod 2008, 78, 958-967.

15. Guthrie HD, Welch GR. Effects of reactive oxygen species on sperm function. Theriogenology 2012, 78, 1700-1708.

16. Hammadeh ME, Dehn C, Hippach M, Zeginiadou T, Stieber M, Georg T, Rosenbaum P, Schmidt W. Comparison between computerized slow-stage and static liquid nitrogen vapour freezing methods with respect to the deleterious effect on chromatin and morphology of spermatozoa from fertile and subfertile men. Int J Androl 2001, 24, 66-72.

17. Jin JX, Lee S, Khoirinaya C, Oh A, Kim GA, Lee BC. Supplementation with spermine during in vitro maturation of porcine oocytes improves early embryonic development after parthenogenetic activation and somatic cell nuclear transfer. J Anim Sci 2016, 94, 963-970.

18. Kasimanickam VR, Kasimanickam RK, Rogens HA. Immunolocalization of retinoic acid receptor-alpha, -beta, and -gamma, in bovine and canine sperm. Theriogenology 2013, 79, 1010-1018.
19. Kim S, Hooper S, Agca C, Agca Y. Post-thaw ATP supplementation enhances cryoprotective effect of iodixanol in rat spermatozoa. Reprod Biol Endocrinol 2016, 14, 5.

20. Mandal A, Klotz KL, Shetty J, Jayes FL, Wolkowicz MJ, Bolling LC, Coonrod SA, Black MB, Diekman AB, Haystead TA, Flickinger CJ, Herr JC. SLLP1, a unique, intra-acrosomal, non-bacteriolytic, c lysozyme-like protein of human spermatozoa. Biol Reprod 2003, 68, 1525-1537.

21. Matás C, Decuadro G, Martínez-Miró S, Gadea J. Evaluation of a cushioned method for centrifugation and processing for freezing boar semen. Theriogenology 2007, 67, 1087-1091.

22. McLaughlin EA, Ford WCL, Hull MGR. The contribution of the toxicity of a glycerol-egg yolk-citrate cryopreservative to the decline in human sperm motility during cryopreservation. J Reprod Fertil 1992, 95, 749-754.

23. Miguel-Jiménez S, Mogas T, Peña AI, Tamargo C, Hidalgo CO, Muiño R, Rodríguez-Gil JE, Morató R. Post-thaw changes in sperm membrane and ROS following cryopreservation of dairy bull semen using four different commercial extenders. In: Physiology of Reproduction in Male and Semen Technology (Abstracts A191E to A205E): 32nd Meeting of the European Embryo Transfer Association (AETE); 9-10 August 2016, Barcelona, Spain.

24. Nagashima JB, Sylvester SR, Nelson JL, Cheong SH, Mukai C, Lambo C, Flanders JA, Meyers-Wallen VN, Songsasen N, Travis AJ. Live births from domestic dog (Canis familiaris) embryos produced by in vitro fertilization. PLoS One 2015, 10, e0143930.

25. Peña AI, Barrio M, Becerra JJ, Quintela LA, Herradón PG. Motile sperm subpopulations in frozen-thawed dog semen: changes after incubation in capacitating conditions and relationship with sperm survival after osmotic stress. Anim Reprod Sci 2012, 133, 214-223.

26. Saragusty J, Gacitua H, Rozenboim I, Arav A. Protective effects of iodixanol during bovine sperm cryopreservation. Theriogenology 2009, 71, 1425-1432.

27. Schneider S, Balbach M, Jan F Jikeli, Fietz D, Nettersheim D, Jostes S, Schmidt R, Kressin M, Bergmann M, Wachten D, Steger K, Schorle H. Re-visiting the Protamine-2 locus: deletion, but not haploinsufficiency, renders male mice infertile. Sci Rep 2016, 6, 36764.

28. Schulte RT, Ohl DA, Sigman M, Smith GD. Sperm DNA damage in male infertility: etiologies, assays, and outcomes. J Assist Reprod Genet 2010, 27, 3-12.

29. Setyawan EMN, Kim MJ, Oh HJ, Kim GA, Jo YK, Lee SH, Choi YB, Lee BC. Maintaining canine sperm function and osmolyte content with multistep freezing protocol and different cryoprotective agents. Cryobiology 2015, 71, 344-349.

30. Setyawan EMN, Kim MJ, Oh HJ, Kim GA, Jo YK, Lee SH, Choi YB, Lee BC. Spermine reduces reactive oxygen species levels and decreases cryocapacitation in canine sperm cryopreservation. Biochem Biophys Res Commun 2016, 479, 927-932.

31. Shin JA, Chung JS, Cho SH, Kim HJ, Yoo YD. Romo1 expression contributes to oxidative stress-induced death of lung epithelial cells. Biochem Biophys Res Commun 2013, 439, 315-320. 
32. Simon HU, Haj-Yehia A, Levi-Schaffer F. Role of reactive oxygen species (ROS) in apoptosis induction. Apoptosis 2000, 5, 415-418.

33. Simon L, Murphy K, Shamsi MB, Liu L, Emery B, Aston KI, Hotaling J, Carrell DT. Paternal influence of sperm DNA integrity on early embryonic development. Hum Reprod 2014, 29, 2402-2412.

34. Swami DS, Kumar P, Malik RK, Saini M, Kumar D, Jan MH. The cryoprotective effect of iodixanol in buffalo semen cryopreservation. Anim Reprod Sci 2017, 179, 20-26.

35. Tremellen K. Oxidative stress and male infertility ${ }^{-}$a clinical perspective. Hum Reprod Update 2008, 14, 243-258.

36. Turrens JF. Mitochondrial formation of reactive oxygen species. J Physiol 2003, 552, 335-344.

37. Van den Berghe F, Paris MCJ, Briggs MB, Farstad WK, Paris DBBP. A two-step dilution tris-egg yolk extender containing Equex STM significantly improves sperm cryopreservation in the African wild dog (Lycaon pictus). Cryobiology 2018, 80, 18-25.

38. Zalata AA, Mokhtar N, Atwa A, Khaled M, Shaker OG. The role of protamine 2 gene expression and caspase 9 activity in male infertility. J Urol 2016, 195, 796-800.

39. Zini A, Boman JM, Belzile E, Ciampi A. Sperm DNA damage is associated with an increased risk of pregnancy loss after IVF and ICSI: systematic review and metaanalysis. Hum Reprod 2008, 23, 2663-2668. 